\title{
Short-term effects of the orthodontic removable traction appliance in the treatment of skeletal Class III malocclusion: A randomized controlled trial
}

\author{
Batool Ahmad Alzabibi ${ }^{1, B-F}$, Ahmad Sharafeddin Burhan ${ }^{1, A, C, E, F}$, Mohammad Younis Hajeer ${ }^{1, A, C, E, F}$, Fehmieh Rafik Nawaya ${ }^{2, A, C, E, F}$ \\ ${ }^{1}$ Department of Orthodontics, Faculty of Dentistry, University of Damascus, Syria \\ ${ }^{2}$ Department of Pediatric Dentistry, Faculty of Dentistry, Syrian Private University, Damascus, Syria \\ A - research concept and design; $\mathrm{B}$ - collection and/or assembly of data; $\mathrm{C}$ - data analysis and interpretation; \\ $D$ - writing the article; $E$ - critical revision of the article; $F$ - final approval of the article
}

Address for correspondence

Mohammad Younis Hajeer

E-mail:myhajeer@gmail.com

Funding sources

The research was funded from the Postgraduate Research Budget of the Faculty of Dentistry at the University of Damascus, Syria (ref. No. 93964302981DEN).

Conflict of interest

None declared

Received on May 6, 2020

Reviewed on July 6, 2020

Accepted on August 11, 2020

Published online on May 28, 2021

Cite as

Alzabibi BA, Burhan AS, Hajeer MY, Nawaya FR. Short-term effects of the orthodontic removable traction appliance in the treatment of skeletal Class III malocclusion: A randomized controlled trial. Dent Med Probl. 2021;58(2):163-172. doi:10.17219/dmp/126304

DOI

$10.17219 / \mathrm{dmp} / 126304$

Copyright

( 2021 by Wroclaw Medical University

This is an article distributed under the terms of the

Creative Commons Attribution 3.0 Unported License (CC BY 3.0)

(https://creativecommons.org/licenses/by/3.0/)

\begin{abstract}
Background. The orthodontic removable traction appliance (ORTA) was introduced as an intraoral removable appliance to treat Class III patients, but the pure treatment effects of ORTA have not been established yet.

Objectives. The aim of the study was to evaluate the skeletal, dental and soft tissue changes following the use of ORTA in treating Class III growing patients, and to compare these changes with those observed in an untreated control group (UCG).

Material and methods. Forty-two patients with Class III malocclusion (mean age: $9.04 \pm 0.84$ years) were randomly allocated to either the intervention group (ORTA) or UCG with a 1:1 allocation ratio. The patients in the ORTA group were treated until a positive overjet was achieved, whereas those in UCG were observed for an average of 6 months. Lateral cephalograms were obtained before (T1) and at the end of the treatment or observation period (T2). Twenty-six variables were used to evaluate treatment changes. The paired and independent $t$ tests were used to detect significant differences within and between the groups, respectively.

Results. Forty-two patients who met the inclusion criteria were included primarily. Two patients in UCG dropped out of the study. Therefore, 40 patients were included in the statistical analyses (ORTA: 21; UCG: 19). The orthodontic removable traction appliance was able to correct Class III malocclusion in a mean treatment time of $4.34 \pm 2.02$ months. The maxilla moved forward by a mean of $1.31^{\circ}$, which was significantly greater than in the case of UCG (i.e., a mean difference of $1.02^{\circ}$ ). The mandible moved significantly backward in the ORTA group (the mean change in SNB: $-1.85^{\circ}$ ) and significantly forward in UCG (the mean change in SNB: $0.97^{\circ}$ ), leaving the overall sagittal skeletal change significantly greater in the ORTA group as compared to UCG (the mean change in ANB: $\left.3.81^{\circ}\right)(p<0.001)$.

Conclusions. In the short term, ORTA seemed to be an effective intraoral removable appliance in the treatment of growing Class III patients.
\end{abstract}

Keywords: malocclusion, angle Class III, removable orthodontic appliances 


\section{Introduction}

Skeletal Class III malocclusion is considered one of the most difficult orthodontic problems to treat. ${ }^{1}$ This condition of malocclusion can result from a wide spectrum of skeletal and dental abnormalities. ${ }^{2}$ The early treatment of Class III malocclusion in growing patients is a matter exceedingly discussed in the literature. ${ }^{3}$

Several studies have recommended early intervention in the case of developing Class III malocclusion to reduce the need for or the complexity of the $2^{\text {nd }}$ phase of treatment, ${ }^{4}$ and to reduce the need for an orthognathic surgery at late adolescence. ${ }^{5}$ Many appliances have been advocated for the treatment of this kind of malocclusion by means of growth modification either in primary or mixed dentition, such as the chin cup 6 and the facemask (FM), ${ }^{7}$ which are considered effective extraoral appliances. However, the lack of esthetics and the bulky size of these devices reduce patients' cooperation and compromise their clinical success. ${ }^{8}$ Therefore, an increased interest in intraoral appliances has been shown in recent years. ${ }^{9}$

The orthodontic removable traction appliance (ORTA) was introduced as an intraoral removable appliance that could be used in conjunction with rapid maxillary expansion (RME) or fixed appliances. It was developed in the 1980s by David Musich as an attempt to overcome the compliance problems encountered in the use of FM. ${ }^{10}$ A quick review of the literature reveals that there is only 1 study published as an MSc thesis in 2012 that evaluates this appliance by comparing its effectiveness with FM. ${ }^{10}$ Within the limitations of the above-mentioned retrospective study, no statistically significant differences in the skeletal and dental values were found between the 2 examined groups except for SNA, which was greater in the FM group as compared to the ORTA group. Thus, the authors concluded that ORTA could be used as another treatment modality for patients with Class III malocclusion. ${ }^{10}$ However, the pure treatment effects of ORTA have not been studied yet, since growth-related changes were not filtered out in the above-mentioned study (i.e., the absence of a control group with no treatment). ${ }^{10}$

Therefore, the objective of the current trial was to evaluate and compare the skeletal, dental and soft tissue changes resulting from the use of ORTA in growing Class III patients with an untreated control group (UCG).

\section{Material and methods}

\section{Trial design and any changes after trial commencement}

This study was a two-arm, parallel-group, randomized controlled trial. It was approved by the local Research
Ethics Committee of the University of Damascus, Syria. It was registered at Clinical.Trials.gov (NCT 03172442). The current study was conducted between May 2017 and February 2019. No changes occurred in the methodology of this study after trial commencement.

\section{Sample size calculation}

The sample size was calculated using the $G$ *Power software, v. 3.1.3 (Franz Faul, University of Kiel, Germany), with the following assumptions: a significance level of 0.05 ; a power of $90 \%$; and a minimal difference in Wits appraisal requiring detection between the 2 treatment groups of $2.5 \mathrm{~mm}$ based on the variability of this measurement in a previous study. ${ }^{1}$ The power analysis showed that 19 patients in each group were required to conduct the two-sample $t$ tests. To compensate for possible dropouts during the trial period, it was decided to enroll 2 additional patients in each group. The patients and their parents were given information sheets and signed informed consent forms.

\section{Participants, eligibility criteria and settings}

The study participants were selected from the patients seeking treatment at the Department of Orthodontics of the University of Damascus, Syria, according to the following criteria: skeletal Class III malocclusion caused by maxillary deficiency and/or mandibular prognathism (2 cephalometric conditions had to be met: $-3^{\circ} \leq \mathrm{ANB} \leq 1.5^{\circ}$ and $-3 \mathrm{~mm} \geq$ Wits appraisal $\geq-9 \mathrm{~mm}$ ); an anterior cross-bite or an edge-to-edge relationship; patients with mixed dentition, aged 8-10 years; and good oral hygiene.

The exclusion criteria were as follows: previous orthodontic treatment; patients with syndromes, clefts or craniofacial abnormalities; patients with facial asymmetry; and patients with missing teeth or periodontal diseases.

\section{Randomization and allocation concealment}

Seventy patients were examined for eligibility. The number of patients who met the inclusion criteria and agreed to participate in the study was 51 . Fortytwo of these participants were randomly chosen, and then assigned randomly to the 2 study groups by using a computer-generated list of random numbers with an allocation ratio of 1:1 (21 patients in each group). The assigned group for each patient was concealed using opaque sealed envelopes that were not opened until the patients' sorting was started (Fig. 1). 


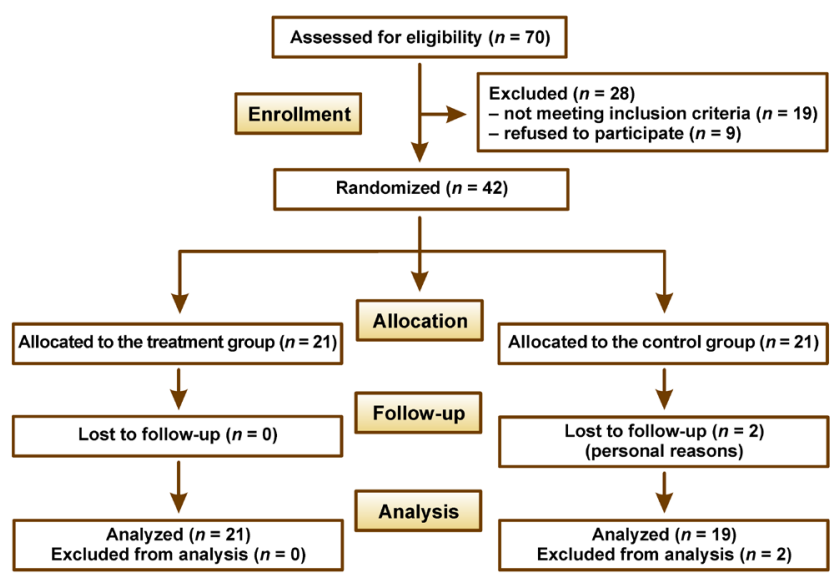

Fig. 1. CONSORT (Consolidated Standards of Reporting Trials) flow diagram of the patients' recruitment and follow-up in the trial

\section{Blinding}

Due to the nature of the trial, blinding of the patients and the clinicians was not applicable. However, all cephalometric radiographs were coded. This ensured that the measurements were carried out by 1 assessor who was totally blinded to the study group (B.A.A.).

\section{Pilot study}

Since this was the first time when this device was applied at the University of Damascus Postgraduate Orthodontic Clinic, a pilot study was performed to detect any problems that could arise with the application of ORTA. The pilot study sample consisted of 6 patients ( 3 boys and 3 girls) meeting the same inclusion criteria as previously mentioned. All of them were treated by means of ORTA according to the design provided in Moore's study. ${ }^{10}$ The pilot study revealed that modifications were needed to solve 2 problems. The first one was the lack of the appliance stability during the application of traction. Therefore, it was decided to increase the number of teeth holding the retentive ridges to at least 6 teeth to ensure the stability of the appliance. The other issue was gingival problems, especially at the vestibular side of the lower incisors. Two out of 6 patients had gingival recession on the central incisors and this was attributed to the inferiorly extended edges of the lower clear plate. Therefore, it was decided to trim the edges exactly above the gingival margins of the lower incisors to prevent any gingival injury.

\section{Intervention group: ORTA}

The 3 components of the RME-assisted ORTA used in this study were as follows: a lower vacuum plate of 1.5-millimeter thickness (Easy-Vac Gasket; 3A MEDES, Goyang, South Korea) with 2 welded buccal buttons (American Orthodontics, Sheboygan, USA) located at the areas between the lateral incisor and the canine on each side, which were used for attaching intermaxillary elastics (Fig. 2A); a Hyrax-type rapid maxillary expander (Lewa-Dental-Feinmechanik, Remchingen, Germany) with 4 bands placed on the posterior teeth (Fig. 2B); and Class III elastics (Fig. 2C).

The banded rapid maxillary expander was fitted on the maxillary permanent first molars and primary first molars. The expansion screw was activated once per day for the first 7 days to disrupt the circum-maxillary sutures in cases without posterior cross-bites. For patients with posterior cross-bites, the expansion procedure continued until the cross-bites were overcorrected (i.e., the palatal cusps of the upper posterior teeth occluded onto the lingual inclines of the buccal cusps of the lower posterior teeth).

On the lower dental arch, the first step was the application of retentive ridges on several teeth. They were placed on the lateral incisor, deciduous canine and deciduous first molar on each side. This was done by applying a composite resin (Medental International, Vista, USA)

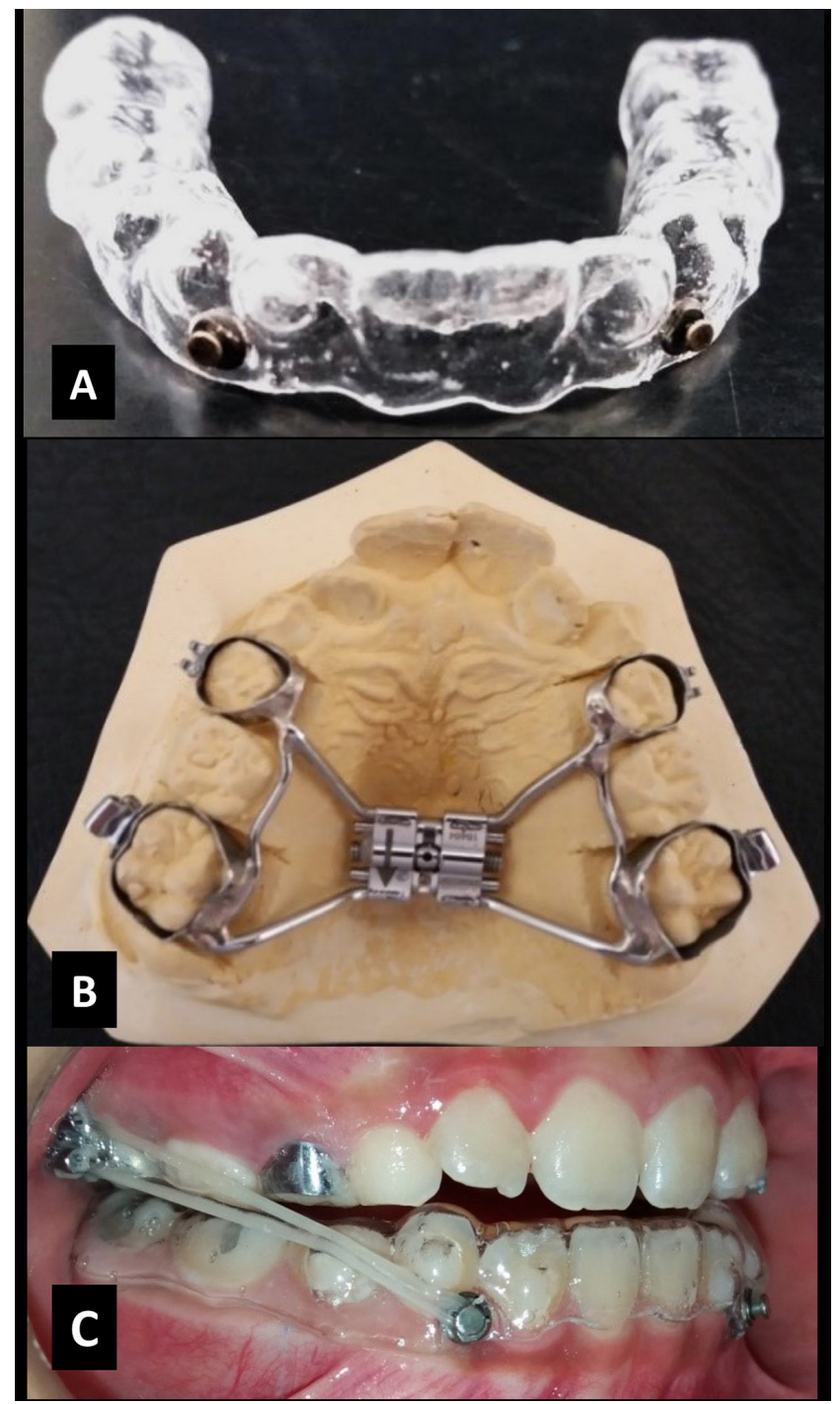

Fig. 2. Orthodontic removable traction appliance (ORTA) used in the current study (A), a Hyrax-type rapid maxillary expander with bands fitted on molars (B) and Class III elastics in their place (C) 
to the surfaces of the chosen tooth as a ridge shape. An alginate impression was taken, then thermoplastic plates were constructed using a specific device (Ministar ${ }^{\circledR}$; Scheu-Dental, Iserlohn, Germany). All clinical procedures were done by the same clinician (B.A.A.).

Elastic traction was started simultaneously with RME. Elastics of a 3/16-inch diameter were attached from the tube of the maxillary permanent first molar to the button in the lower vacuum plate on each side to produce forces ranging from 220 to $240 \mathrm{~g}$, as measured by a force gauge. The patients were instructed to wear ORTA with Class III elastics $24 \mathrm{~h}$ per day, except during eating times, and they were asked to change the elastics daily. All patients were treated until at least a 3-millimeter positive overjet was achieved and this was considered the T2 point in the ORTA group. The patients were then instructed to wear the appliance at nighttime only for 2-3 months to maintain the achieved correction. The patients in this group were seen monthly to monitor the achieved results and it was planned to intervene if any significant relapse occurred.

The patients in UCG were left untreated and they were observed for about 6 months. Their records were obtained at the beginning and the end of this period. According to the local Research Ethics Committee guidelines, these patients were treated by postgraduate students immediately after the end of the observation period.

\section{Outcome measurements}

Lateral cephalograms of each patient were obtained at the beginning (T1) and the end of the treatment or observation period (T2). All radiographs were taken with maximum intercuspation, relaxed lips and a natural head position. The radiographs were hand-traced and measured by the same researcher (B.A.A.) by using a conventional lightbox and a 0.3-millimeter lead pencil. The reference planes used in this study were the anterior cranial base plane $(\mathrm{SN})$, the Frankfort horizontal plane $(\mathrm{FH})$ and the esthetics line of Ricketts (E-line). In order to evaluate dentoskeletal and soft tissue changes, 11 linear and 15 angular parameters were used in this study (Fig. 3 and Fig. 4).

\section{Method error}

Fifteen randomly selected cephalograms were retraced and remeasured 1 month after the first tracing to determine the method error. The paired $t$ tests showed no significant differences between the 2 measurements, and the mean errors for angular and linear measurements were less than $0.6^{\circ}$ and $0.6 \mathrm{~mm}$, respectively, according to Dahlberg's formula, ${ }^{11}$ indicating a negligible error. The intraclass correlation coefficients were greater than 0.90 for all variables, with the majority being greater than 0.95 , thus confirming the high reliability of the measurements.

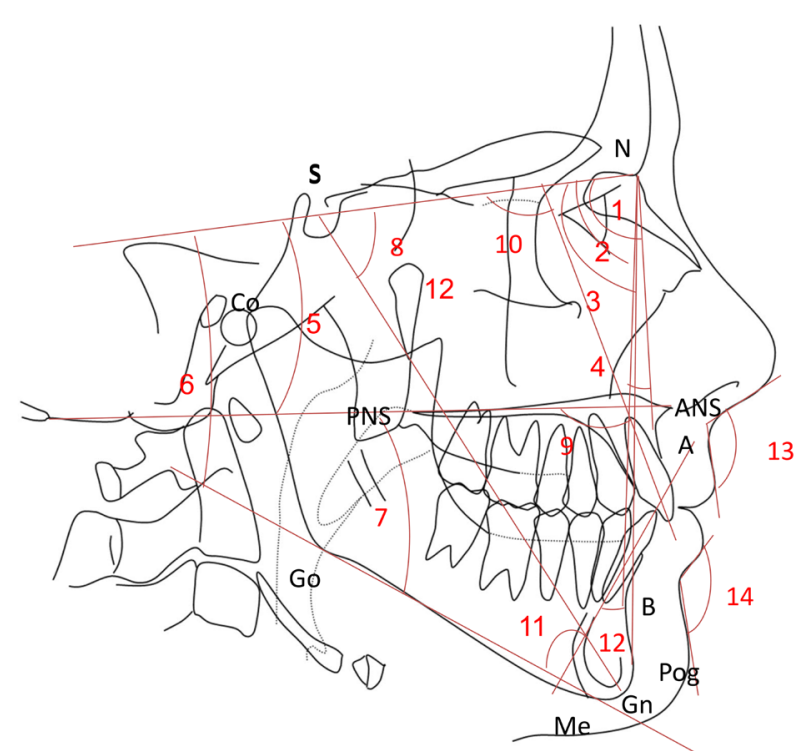

Fig. 3. Angular cephalometric measurements

1: SNA; 2: SNB; 3: SN-Pog; 4: ANB; 5: SN-SPP; 6: SN-GoMe; 7: SPP-GoMe; 8: Y-axis; 9: U1-SPP; 10: U1-SN; 11: L1-GoMe; 12: L1-NB; 13: Nasolab;

14: Mentolab.

$\mathrm{S}$ - sella; $\mathrm{N}$ - nasion; $\mathrm{A}$ - point $\mathrm{A} ; \mathrm{B}$ - point $\mathrm{B}$; Pog - pogonion; SPP - spinal palatal plane; Go - gonion; Me - menton; U1 - upper incisor; L1 - lower incisor; Nasolab - nasolabial angle; Mentolab - mentolabial; Gn - gnathion.

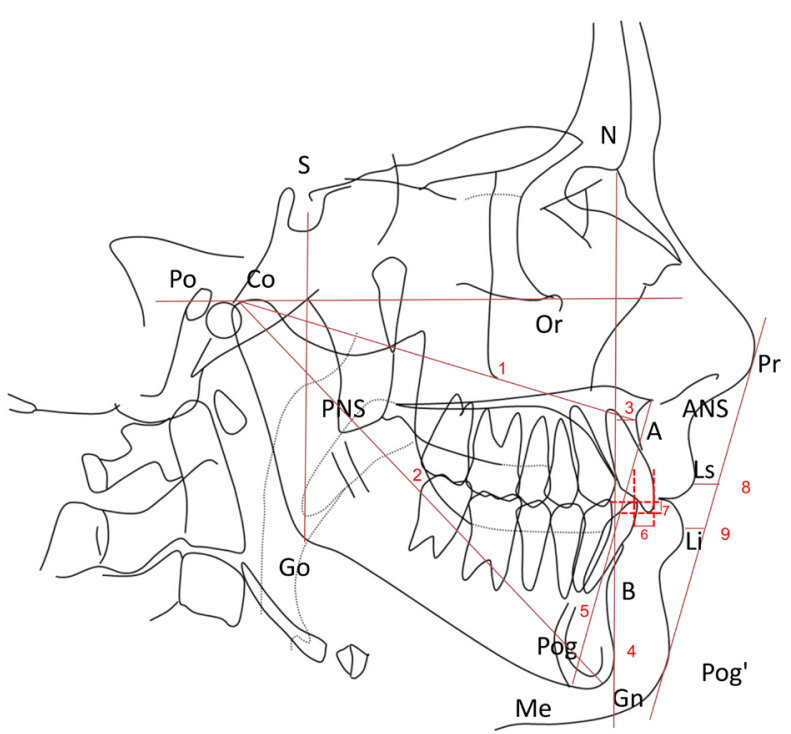

Fig. 4. Linear cephalometric measurements

1: Co-A; 2: Co-Gn; 3: A-to-N perp; 4: Pog-to-N perp; 5: ANS-Me; 6: overjet; 7: overbite, 8: Ls-Esth; 9: Li-Esth.

Co - condylion; perp - perpendicular; Ls - labialis superior; Esth - esthetics line of Ricketts (E-line); Li - labialis inferior; Or - orbitale; Po - porion.

\section{Statistical analyses}

All statistical analyses were performed with the IBM SPSS Statistics for Windows software, v. 22 (IBM Corp., Armonk, USA). The Kolmogorov-Smirnov test showed a normal distribution of all variables; therefore, parametric statistics were applied. The intragroup comparisons were analyzed with the paired $t$ tests and the intergroup 
comparison was evaluated with the $t$ test for independent groups. Gender distribution was evaluated using Pearson's $\chi^{2}$ test. The level of significance was set at 5\%.

\section{Results}

Forty-two patients who met the inclusion criteria were included primarily (21 patients in each group). Two patients in UCG dropped out of the study for personal reasons. Therefore, 40 patients were included in the statistical analyses. The ORTA group consisted of 21 patients (12 boys, 9 girls; mean age: 8.95 years), whereas UCG consisted of 19 patients ( 8 boys, 11 girls; mean age: 9.14 years) (Table 1).

There were no statistically significant differences between the 2 groups for the following data: age $(p=0.458)$; gender distribution ( $p=0.342)$; and treatment duration (a mean of 18.6 weeks) and the observation period (a mean of 22.1 weeks $(p=0.094)$ (Table 1 ).

The analysis of cephalometric variables in the ORTA group and UCG at T1 showed no statistically significant differences between the 2 groups (Table 2). In the ORTA group, the cephalometric measurements related to the maxilla (i.e., SNA, Co-A and A-to-N perp) showed significant mean increases of $1.31^{\circ}, 2.92 \mathrm{~mm}$ and $1.41 \mathrm{~mm}$, respectively $(p<0.001)$, whereas no significant increases were detected in UCG $(p>0.05)$ (Table 3). Differences between the 2 groups in SNA, Co-A and A-to-N perp showed a greater average improvement in the ORTA group over the controls of $1.02^{\circ}, 2.26 \mathrm{~mm}$ and $1.39 \mathrm{~mm}$, respectively $(p<0.01)$ (Table 4$)$.

In the ORTA group, the mandible significantly moved backward, i.e., SNB, SN-Pog and Pog-to-N perp showed mean decreases of $1.85^{\circ}, 1.66^{\circ}$ and $2.17 \mathrm{~mm}$, respectively, whereas in UCG, significant mean increases of $0.97^{\circ}, 0.84^{\circ}$ and $1.50 \mathrm{~mm}$ were observed, respectively. The analysis showed that differences between the mean changes across the groups for the mandibular position were significant $\left(-2.82^{\circ},-2.51^{\circ}\right.$ and $-3.67 \mathrm{~mm}$ for SNB, SN-Pog and Pog-to-N, respectively $(p<0.001)$ (Table 3 and Table 4$)$.

Table 1. Basic sample characteristics

\begin{tabular}{|l|c|c|c|}
\multicolumn{1}{|c|}{ Characteristic } & \multicolumn{1}{c|}{$\begin{array}{c}\text { ORTA } \\
(n=21)\end{array}$} & $\begin{array}{c}\text { UCG } \\
(n=19)\end{array}$ & $p$-value \\
\hline $\begin{array}{l}\text { Age } \\
{[\text { years }]} \\
M \pm S D\end{array}$ & $8.95 \pm 0.88$ & $9.14 \pm 0.80$ & $0.458^{\mathrm{a}}$ \\
$\begin{array}{l}\text { Treatment duration/ } \\
\text { observation period } \\
{[\text { weeks }]}\end{array}$ & $18.62 \pm 8.65$ & $22.11 \pm 1.94$ & $0.094^{\mathrm{a}}$ \\
$\begin{array}{l}\mathrm{M} \pm S D \\
\begin{array}{l}\text { Gender distribution } \\
\text { males/females }\end{array}\end{array}$ & $12 / 9$ & $8 / 11$ & $0.342^{\mathrm{b}}$ \\
\hline
\end{tabular}

ORTA - orthodontic removable traction appliance group;

UCG - untreated control group; $M$ - mean; SD - standard deviation;

${ }^{\mathrm{a}}$ independent $t$ test; ${ }^{\mathrm{b}} \mathrm{X}^{2}$ test.
Table 2. Comparison of the initial measurements between the 2 groups

\begin{tabular}{|c|c|c|c|c|c|}
\hline \multirow{2}{*}{$\begin{array}{c}\text { Cephalometric } \\
\text { parameter }\end{array}$} & \multicolumn{2}{|c|}{$\begin{array}{c}\text { ORTA } \\
(n=21)\end{array}$} & \multicolumn{2}{|c|}{$\begin{array}{c}\text { UCG } \\
(n=19)\end{array}$} & \multirow{2}{*}{$p$-value* } \\
\hline & $M$ & $S D$ & $M$ & $S D$ & \\
\hline SNA $\left[^{\circ}\right]$ & 79.17 & 4.92 & 78.08 & 4.99 & 0.492 \\
\hline Co-A $[\mathrm{mm}]$ & 74.48 & 3.57 & 75.10 & 3.44 & 0.576 \\
\hline A-to-N perp [mm] & -1.49 & 3.15 & -1.00 & 2.16 & 0.577 \\
\hline $\mathrm{SNB}\left[^{\circ}\right]$ & 79.33 & 4.26 & 78.92 & 3.37 & 0.738 \\
\hline SN-Pog [ [ $]$ & 79.40 & 4.43 & 79.21 & 3.31 & 0.877 \\
\hline Co-Gn [mm] & 98.97 & 5.54 & 100.65 & 7.21 & 0.410 \\
\hline Pog-to-N perp [mm] & -2.73 & 6.12 & -0.68 & 3.21 & 0.201 \\
\hline Wits appraisal [mm] & -6.59 & 2.29 & -6.23 & 2.04 & 0.598 \\
\hline ANB $\left[^{\circ}\right]$ & -0.17 & 1.98 & -0.84 & 2.69 & 0.368 \\
\hline $\mathrm{SN}-\mathrm{SPP}\left[{ }^{\circ}\right]$ & 10.00 & 3.41 & 9.61 & 2.93 & 0.698 \\
\hline SN-GoMe $\left[{ }^{\circ}\right]$ & 35.26 & 4.93 & 35.32 & 3.14 & 0.968 \\
\hline SPP-GoMe $\left[^{\circ}\right]$ & 25.24 & 4.31 & 25.71 & 3.13 & 0.697 \\
\hline Björk's sum [] & 393.98 & 5.15 & 394.37 & 3.10 & 0.775 \\
\hline Y-axis [0] & 66.52 & 4.42 & 67.13 & 3.18 & 0.624 \\
\hline ANS-Me [mm] & 56.65 & 4.45 & 57.90 & 4.90 & 0.403 \\
\hline S-Go/N-Me [\%] & 62.44 & 3.77 & 62.06 & 2.31 & 0.707 \\
\hline U1-SPP [] & 108.93 & 6.61 & 111.84 & 6.02 & 0.155 \\
\hline U1-SN [] & 99.02 & 6.54 & 102.24 & 7.32 & 0.151 \\
\hline L1-GoMe [] & 89.07 & 5.07 & 90.58 & 3.73 & 0.295 \\
\hline L1-NB [ $\left.{ }^{\circ}\right]$ & 23.81 & 4.28 & 24.92 & 5.11 & 0.459 \\
\hline Overjet [mm] & -1.98 & 1.19 & -1.58 & 1.48 & 0.352 \\
\hline Overbite [mm] & 1.58 & 1.17 & 1.09 & 1.60 & 0.270 \\
\hline Ls-Esth [mm] & -2.98 & 2.24 & -2.66 & 1.86 & 0.625 \\
\hline Li-Esth [mm] & 0.05 & 2.13 & 0.28 & 1.73 & 0.707 \\
\hline Nasolab $\left[^{\circ}\right]$ & 110.21 & 9.50 & 110.34 & 5.85 & 0.960 \\
\hline Mentolab [ $\left.{ }^{\circ}\right]$ & 133.57 & 17.75 & 138.55 & 15.98 & 0.359 \\
\hline
\end{tabular}

* independent $t$ test.

In terms of intermaxillary sagittal relationship changes, both groups changed significantly over time; however, ORTA introduced favorable changes (a mean change of Wits appraisal of $5.24 \mathrm{~mm}$ and of ANB of $3.12^{\circ}$ ), while the parameters for the controls worsened $(-0.72 \mathrm{~mm}$ for Wits appraisal and $-0.69^{\circ}$ for ANB). Differences across the groups were significant $(5.96 \mathrm{~mm}$ for Wits appraisal and $3.81^{\circ}$ for ANB) (Table 3 and Table 4 ).

In terms of vertical relationship changes, the patients in the ORTA group had a significant clockwise rotation and a significant mean increase in the vertical dimension (SN-GoMe: $1.12^{\circ}$; Björk's sum: $2.40^{\circ}$ ). Conversely, the patients in UCG showed a non-significant anterior rotation (SN-GoMe: $-0.85^{\circ}$; Björk's sum: $-0.87^{\circ}$ ). The mean increases in the vertical dimension were significantly greater in the ORTA group than in the controls (SN-GoMe: $1.97^{\circ}$; Björk's sum: $3.27^{\circ}$ ), while no significant changes were found in SN-SPP and SPP-GoMe between the 2 groups (Table 3 and Table 4). 
Table 3. Descriptive statistics of changes in the 2 groups and the results of significance tests

\begin{tabular}{|c|c|c|c|c|c|c|c|c|}
\hline \multirow{2}{*}{$\begin{array}{l}\text { Cephalometric } \\
\text { parameter }\end{array}$} & \multicolumn{3}{|c|}{$\begin{array}{c}\text { ORTA } \\
(n=21)\end{array}$} & \multirow{2}{*}{$p$-value ${ }^{\dagger}$} & \multicolumn{3}{|c|}{$\begin{array}{c}\text { UCG } \\
(n=19)\end{array}$} & \multirow{2}{*}{$p$-value ${ }^{\dagger}$} \\
\hline & T1 & $\mathrm{T} 2$ & $\mathrm{~T} 2-\mathrm{T} 1$ & & T1 & $\mathrm{T} 2$ & $\mathrm{~T} 2-\mathrm{T} 1$ & \\
\hline SNA $\left[^{\circ}\right]$ & $79.17 \pm 4.92$ & $80.48 \pm 4.70$ & $1.31 \pm 0.83$ & $<0.001^{* * *}$ & $78.08 \pm 4.99$ & $78.37 \pm 4.47$ & $0.29 \pm 0.89$ & 0.172 \\
\hline Co-A [mm] & $74.48 \pm 3.57$ & $77.40 \pm 3.61$ & $2.92 \pm 1.66$ & $<0.001^{* * *}$ & $75.10 \pm 3.44$ & $75.76 \pm 2.89$ & $0.66 \pm 2.21$ & 0.215 \\
\hline A-to-N perp [mm] & $-1.49 \pm 3.15$ & $-0.08 \pm 3.44$ & $1.41 \pm 1.45$ & $<0.001^{* * *}$ & $-1.00 \pm 2.16$ & $-0.98 \pm 2.24$ & $0.02 \pm 1.35$ & 0.948 \\
\hline SNB $\left[^{\circ}\right]$ & $79.33 \pm 4.26$ & $77.48 \pm 4.06$ & $-1.85 \pm 1.06$ & $<0.001^{* * *}$ & $78.92 \pm 3.37$ & $79.89 \pm 3.07$ & $0.97 \pm 1.06$ & $0.001^{* *}$ \\
\hline SN-Pog $\left[^{\circ}\right]$ & $79.40 \pm 4.43$ & $77.74 \pm 4.22$ & $-1.66 \pm 1.02$ & $<0.001^{* * *}$ & $79.21 \pm 3.31$ & $80.05 \pm 3.16$ & $0.84 \pm 1.16$ & $0.005^{* *}$ \\
\hline Co-Gn [mm] & $98.97 \pm 5.54$ & $99.55 \pm 4.70$ & $0.58 \pm 2.20$ & 0.239 & $100.65 \pm 7.21$ & $102.26 \pm 6.83$ & $1.61 \pm 2.51$ & $0.012^{*}$ \\
\hline Pog-to-N perp [mm] & $-2.73 \pm 6.12$ & $-4.90 \pm 6.60$ & $-2.17 \pm 3.28$ & $0.006^{* *}$ & $-0.68 \pm 3.21$ & $0.82 \pm 4.86$ & $1.50 \pm 2.60$ & $0.021^{*}$ \\
\hline Wits appraisal [mm] & $-6.59 \pm 2.29$ & $-1.35 \pm 3.31$ & $5.24 \pm 2.68$ & $<0.001^{* * *}$ & $-6.23 \pm 2.04$ & $-6.95 \pm 2.28$ & $-0.72 \pm 1.09$ & $0.010^{*}$ \\
\hline ANB $\left[^{\circ}\right]$ & $-0.17 \pm 1.98$ & $2.95 \pm 1.94$ & $3.12 \pm 1.07$ & $<0.001^{* * *}$ & $-0.84 \pm 2.69$ & $-1.53 \pm 2.83$ & $-0.69 \pm 0.77$ & $0.001^{* *}$ \\
\hline SN-SPP $\left[^{\circ}\right]$ & $10.00 \pm 3.41$ & $9.81 \pm 3.17$ & $-0.19 \pm 1.75$ & 0.623 & $9.61 \pm 2.93$ & $8.58 \pm 2.86$ & $-1.03 \pm 1.45$ & $0.006^{* *}$ \\
\hline $\mathrm{SN}-\mathrm{GoMe}\left[^{\circ}\right]$ & $35.26 \pm 4.93$ & $36.38 \pm 5.09$ & $1.12 \pm 1.45$ & $0.002^{* *}$ & $35.32 \pm 3.14$ & $34.47 \pm 2.84$ & $-0.85 \pm 1.76$ & 0.052 \\
\hline SPP-GoMe $\left[^{\circ}\right]$ & $25.24 \pm 4.31$ & $26.57 \pm 4.96$ & $1.33 \pm 2.15$ & $0.010^{*}$ & $25.71 \pm 3.13$ & $25.84 \pm 3.24$ & $0.13 \pm 2.15$ & 0.793 \\
\hline Björk's sum [] & $393.98 \pm 5.15$ & $396.38 \pm 4.92$ & $2.40 \pm 2.27$ & $<0.001^{* * *}$ & $394.37 \pm 3.10$ & $393.50 \pm 2.65$ & $-0.87 \pm 1.61$ & $0.031^{*}$ \\
\hline Y-axis [ $\left[^{\circ}\right]$ & $66.52 \pm 4.42$ & $68.43 \pm 4.40$ & $1.91 \pm 1.09$ & $<0.001^{* * *}$ & $67.13 \pm 3.18$ & $66.50 \pm 2.51$ & $-0.63 \pm 1.42$ & 0.069 \\
\hline ANS-Me [mm] & $56.65 \pm 4.45$ & $58.49 \pm 4.28$ & $1.84 \pm 1.83$ & $<0.001^{* * *}$ & $57.90 \pm 4.90$ & $57.72 \pm 4.92$ & $-0.18 \pm 1.55$ & 0.616 \\
\hline S-Go/N-Me [\%] & $62.44 \pm 3.77$ & $61.08 \pm 3.51$ & $-1.36 \pm 1.62$ & $<0.001^{* * *}$ & $62.06 \pm 2.31$ & $62.82 \pm 2.09$ & $0.76 \pm 1.19$ & $0.013^{*}$ \\
\hline U1-SPP [] & $108.93 \pm 6.61$ & $112.29 \pm 5.64$ & $3.36 \pm 3.06$ & $<0.001^{* * *}$ & $111.84 \pm 6.02$ & $111.24 \pm 6.04$ & $-0.60 \pm 2.83$ & 0.363 \\
\hline U1-SN [] & $99.02 \pm 6.54$ & $101.98 \pm 5.83$ & $2.96 \pm 2.67$ & $<0.001^{* * *}$ & $102.24 \pm 7.32$ & $102.74 \pm 6.72$ & $0.50 \pm 2.97$ & 0.473 \\
\hline L1-NB $\left[^{\circ}\right]$ & $23.81 \pm 4.28$ & $16.07 \pm 4.78$ & $-7.74 \pm 4.37$ & $<0.001^{* * *}$ & $24.92 \pm 5.11$ & $24.45 \pm 6.19$ & $-0.47 \pm 2.81$ & 0.472 \\
\hline Overjet [mm] & $-1.98 \pm 1.19$ & $3.89 \pm 1.09$ & $5.87 \pm 1.39$ & $<0.001^{* * *}$ & $-1.58 \pm 1.48$ & $-1.91 \pm 1.35$ & $-0.33 \pm 0.74$ & 0.062 \\
\hline Overbite [mm] & $1.58 \pm 1.17$ & $2.20 \pm 2.30$ & $0.62 \pm 1.84$ & 0.135 & $1.09 \pm 1.60$ & $1.30 \pm 1.59$ & $0.21 \pm 0.50$ & 0.071 \\
\hline Ls-Esth [mm] & $-2.98 \pm 2.24$ & $-1.95 \pm 2.63$ & $1.03 \pm 1.65$ & $0.010^{*}$ & $-2.66 \pm 1.86$ & $-3.40 \pm 2.49$ & $-0.74 \pm 1.79$ & 0.086 \\
\hline Li-Esth [mm] & $0.05 \pm 2.13$ & $-0.75 \pm 2.67$ & $-0.80 \pm 1.58$ & $0.030^{*}$ & $0.28 \pm 1.73$ & $0.08 \pm 1.82$ & $-0.20 \pm 0.98$ & 0.369 \\
\hline Nasolab [º] & $110.21 \pm 9.50$ & $111.33 \pm 8.25$ & $1.12 \pm 10.03$ & 0.615 & $110.34 \pm 5.85$ & $109.50 \pm 9.20$ & $-0.84 \pm 8.20$ & 0.660 \\
\hline Mentolab [] & $133.57 \pm 17.75$ & $130.12 \pm 18.50$ & $-3.45 \pm 15.39$ & 0.316 & $138.55 \pm 15.98$ & $140.34 \pm 14.43$ & $1.79 \pm 4.95$ & 0.132 \\
\hline
\end{tabular}

$\mathrm{T} 1$ - at the beginning of the treatment or observation period; $\mathrm{T} 2$ - at the end of the treatment or observation period;

${ }^{*} p \leq 0.05 ;{ }^{* *} p<0.01 ;{ }^{* * *} p<0.001 ;{ }^{\dagger}$ paired $t$ test.

Data presented as $M \pm S D$.

The maxillary incisors proclined in the ORTA group (U1-SPP: $3.36 \pm 3.02^{\circ}$; U1-SN: $2.96 \pm 2.67^{\circ}$ ), while no changes were observed in UCG (U1-SPP: $-0.60 \pm 2.83^{\circ}$; U1-SN: $0.50 \pm 2.97^{\circ}$ ). Differences between the 2 groups were significant for maxillary incisor protrusion (U1-SPP: $3.96^{\circ} ; p<0.001$ and $\left.\mathrm{U} 1-\mathrm{SN}: 2.45^{\circ} ; p=0.009\right)$. The mandibular incisors retroclined significantly in the ORTA group (L1-GoMe: $-7.38 \pm 4.38^{\circ}$; L1-NB: $-7.74 \pm 4.37^{\circ}$ ), while no significant changes were observed in UCG (Li-GoMe: $-0.32 \pm 1.98^{\circ}$; L1-NB: $-0.47 \pm 2.81^{\circ}$ ). Differences in mandibular incisor retroclination were significant between the 2 groups (L1-GoMe: $-7.06^{\circ}$ and L1-NB: $\left.-7.27^{\circ} ; p<0.001\right)$. Overjet improved significantly more in the ORTA group $(6.20 \mathrm{~mm} ; p<0.001)$, whereas no significant differences were found in overbite in either group, nor between the 2 groups (Table 3 and Table 4).

Regarding soft tissues, the upper lip moved significantly forward in the ORTA group (Ls-Esth: $1.03 \pm 1.65 \mathrm{~mm}$ ), whereas in the control group, the upper lip moved backward (Ls-Esth: $-0.74 \pm 1.79 \mathrm{~mm}$ ), resulting in a significant difference between the groups (Ls-Esth: $1.77 \mathrm{~mm}$; $p=0.002$ ) (Table 3 and Table 4 ).

\section{Harm}

No harm was encountered in the current research project. 
Table 4. Descriptive statistics of differences between the 2 groups in the amount of change observed between T1 and T2, and the results of significance tests

\begin{tabular}{|c|c|c|c|c|c|c|c|}
\hline \multirow[t]{2}{*}{ Cephalometric parameter } & \multicolumn{2}{|c|}{$\begin{array}{c}\text { ORTA } \\
(n=21)\end{array}$} & \multicolumn{2}{|c|}{$\begin{array}{c}\text { UCG } \\
(n=19)\end{array}$} & \multirow[t]{2}{*}{ Difference } & \multirow[t]{2}{*}{$t$-value } & \multirow[t]{2}{*}{$p$-value ${ }^{\dagger}$} \\
\hline & $M$ & $S D$ & $M$ & $S D$ & & & \\
\hline $\mathrm{SNA}\left[^{\circ}\right]$ & 1.31 & 0.83 & 0.29 & 0.89 & 1.02 & 3.760 & $0.001^{* *}$ \\
\hline Co-A $[\mathrm{mm}]$ & 2.92 & 1.66 & 0.66 & 2.21 & 2.26 & 3.686 & $0.001^{* *}$ \\
\hline A-to-N perp [mm] & 1.41 & 1.45 & 0.02 & 1.35 & 1.39 & 3.123 & $0.003^{* *}$ \\
\hline $\mathrm{SNB}\left[^{\circ}\right]$ & -1.85 & 1.06 & 0.97 & 1.06 & -2.82 & -8.424 & $<0.001^{* * *}$ \\
\hline SN-Pog $\left[^{\circ}\right]$ & -1.66 & 1.02 & 0.84 & 1.16 & -2.51 & -7.306 & $<0.001^{* * *}$ \\
\hline Co-Gn $[\mathrm{mm}]$ & 0.58 & 2.20 & 1.61 & 2.51 & -1.03 & -1.383 & 0.175 \\
\hline Pog-to-N perp [mm] & -2.17 & 3.28 & 1.50 & 2.60 & -3.67 & -3.906 & $<0.001^{* * *}$ \\
\hline Wits appraisal [mm] & 5.24 & 2.68 & -0.72 & 1.09 & 5.96 & 9.040 & $<0.001^{* * *}$ \\
\hline ANB $\left[^{\circ}\right]$ & 3.12 & 1.07 & -0.69 & 0.77 & 3.81 & 12.782 & $<0.001^{* * *}$ \\
\hline $\mathrm{SN}-\mathrm{SPP}\left[^{\circ}\right]$ & -0.19 & 1.75 & -1.03 & 1.45 & 0.84 & 1.636 & 0.110 \\
\hline SN-GoMe $\left[^{\circ}\right]$ & 1.12 & 1.45 & -0.85 & 1.76 & 1.97 & 3.857 & $<0.001^{* * *}$ \\
\hline SPP-GoMe $\left[^{\circ}\right]$ & 1.33 & 2.15 & 0.13 & 2.15 & 1.20 & 1.763 & 0.086 \\
\hline Björk's sum $\left[^{\circ}\right]$ & 2.40 & 2.27 & -0.87 & 1.61 & 3.27 & 5.199 & $<0.001^{* * *}$ \\
\hline Y-axis $\left[^{\circ}\right]$ & 1.91 & 1.09 & -0.63 & 1.42 & 2.54 & 6.363 & $<0.001^{* * *}$ \\
\hline ANS-Me [mm] & 1.84 & 1.83 & -0.18 & 1.55 & 2.02 & 3.742 & $0.001^{* *}$ \\
\hline S-Go/N-Me [\%] & -1.36 & 1.62 & 0.76 & 1.19 & -2.12 & -4.668 & $<0.001^{* * *}$ \\
\hline U1-SPP $\left[^{\circ}\right]$ & 3.36 & 3.06 & -0.60 & 2.83 & 3.96 & 4.241 & $<0.001^{* * *}$ \\
\hline U1-SN [] & 2.95 & 2.67 & 0.50 & 2.97 & 2.45 & 2.750 & $0.009^{* *}$ \\
\hline L1-GoMe [] & -7.38 & 4.38 & -0.32 & 1.98 & -7.06 & -6.452 & $<0.001^{* * *}$ \\
\hline L1-NB [ [] & -7.74 & 4.37 & -0.47 & 2.81 & -7.27 & -6.172 & $<0.001^{* * *}$ \\
\hline Overjet [mm] & 5.87 & 1.39 & -0.33 & 0.74 & 6.20 & 17.309 & $<0.001^{* * *}$ \\
\hline Overbite [mm] & 0.62 & 1.84 & 0.21 & 0.50 & 0.41 & 0.934 & 0.356 \\
\hline Ls-Esth [mm] & 1.03 & 1.65 & -0.74 & 1.79 & 1.77 & 3.267 & $0.002^{* *}$ \\
\hline Li-Esth [mm] & -0.80 & 1.58 & -0.20 & 0.98 & -0.60 & -1.413 & 0.166 \\
\hline Nasolab [ํ] & 1.12 & 10.03 & -0.84 & 8.20 & 1.96 & 0.673 & 0.505 \\
\hline Mentolab [º] & -3.45 & 15.39 & 1.79 & 4.95 & -5.24 & -1.419 & 0.164 \\
\hline
\end{tabular}

${ }^{*} p \leq 0.05 ;{ }^{* *} p<0.01 ;{ }^{* * *} p<0.001 ;{ }^{\dagger}$ independent $t$ test.

\section{Discussion}

To the best of our knowledge, this is the first randomized controlled trial evaluating the skeletal, dental and soft tissue changes following the use of ORTA in growing Class III patients, and comparing these changes with an untreated control group.

The analysis of homogeneity between the 2 groups in terms of age, gender distribution and cephalometric variables indicated that the 2 groups were very similar and the applied randomization procedure generated 2 wellmatched groups.

Since this was the first time when ORTA was applied at the University of Damascus Postgraduate Orthodontic Clinics, it was necessary to conduct a pilot study. This study led to 2 important modifications in the treatment protocol: increasing the number of teeth with retentive ridges to ensure the stability of the appliance; and shortening the edges of the device to prevent gingival impingement. This may have provided better results as compared to those achieved with earlier designs.

Although still controversial, RME might disarticulate the maxilla and initiate a cellular response in the sutures, thereby allowing a more positive reaction to protraction forces, which may be beneficial in the early treatment of Class III malocclusion. ${ }^{12-14}$ Therefore, in this study, RME was applied in every treated patient in order to release the circumferential maxillary sutures or to correct posterior cross-bites in case they were found, which also standardized the clinical intervention. 
The mean treatment duration in the present study was 18.62 weeks (4.34 months), which was less than that in Moore's study (6.96 months). ${ }^{10}$ The additional time in Moore's study could be attributed to the fact that records were not always taken at the application or removal of the appliance. Also, traction in Moore's study started following RME, which may have lengthened the overall treatment time, whereas traction in the current study started at the same time as using the RME appliance.

The orthodontic removable traction appliance was able to induce significantly greater advancement of the maxilla as compared to the control group, which means that ORTA had a favorable effect on the maxilla and contributed to the correction of Class III malocclusion. The amount of increase in SNA in the current study was approx. 3 times greater than that observed in Moore's study (an average increase of $0.4^{\circ}$ ). ${ }^{10}$ The greater amount of movement in point $\mathrm{A}$ in this study could be attributed to the following reasons: the age range was 3.1-12.1 years in the previously published retrospective study, while it was 8-10 years in the present work (including younger children might have compromised compliance with appliance wear); the magnitude of the traction forces was not fixed at a specific level, but was adjusted to patients' age, while it ranged between 220 and $240 \mathrm{~g}$ in the present study; the fact that traction was applied after finishing RME in the previous study, while in the current study, traction was applied simultaneously with RME.

The amount of SNA increase observed in the present study was similar to that reported in a recent meta-analysis on the effects of RME + FM (an average increase of $\left.1.39^{\circ}\right) .{ }^{15}$ Therefore, ORTA could be considered as an alternative modality to treat mild or moderate cases of retrusive maxilla; a conclusion that was arrived at in a recently published systematic review. ${ }^{16}$ Increases in the control group in terms of mandibular sagittal growth and position were significantly unfavorable. These findings are in line with a previous study, which confirmed that in untreated patients with Class III malocclusion, the deformity increased over time. ${ }^{2}$

Although a difference between the 2 groups was not significant in terms of change in the length of the mandible $(\mathrm{Co}-\mathrm{Gn})$, that difference $(-1.03 \mathrm{~mm})$ indicated that the forces applied through the device played a role in reducing the growth of the mandible in the sagittal plane. This may suggest that ORTA not only helped in maxillary advancement, but also restrained mandibular growth to some extent. An insignificant increase in Co-Gn in the treatment group was found to be smaller than that reported by Majanni and Hajeer, regarding the groups treated with bone-anchored intermaxillary traction or the removable mandibular retractor (RMR). ${ }^{17}$ This can be explained by the fact that their groups' age means were greater than those in the current study.

The sagittal relationship between the 2 jaws in the treatment group significantly improved as a result of the anterior movement of the maxilla and the posterior movement with a clockwise rotation of the mandible, which was reflected by significant increases in ANB (the average increase of $3.12^{\circ} ; p<0.001$ ) and Wits appraisal (the average increase of $5.24 \mathrm{~mm} ; p<0.001)$. This increase in ANB is consistent with previous studies by Ngan et al. ${ }^{13}$ and Nienkemper et al., ${ }^{18}$ applying RME and protraction FM. Lin et al. in their meta-analysis showed that FM induced an improvement in the intermaxillary sagittal relationship with a mean ANB change of $2.92^{\circ}{ }^{19}$ An increase in ANB was also greater when using ORTA as compared to other devices, such as $\mathrm{RMR}^{17}$ or the modified tandem appliance. ${ }^{20}$

When comparing the 2 groups, a decrease in SNB was approx. triple the amount of increase in SNA. In other words, $3 / 4$ of the improvement in ANB could be attributed to mandibular changes in the form of clockwise rotation. Therefore, Class III patients with mandibular prognathism that are able to tolerate a mandibular clockwise rotation as part of their treatment can be treated with ORTA, as such cases were included and successfully treated with the proposed protocol.

In this study, the mandible in the treatment group showed a significant clockwise rotation (a mean of $1.12^{\circ}$ ) and significant increases in the vertical dimension (ANS-Me: 1.84; $p<0.001$ and Björk's sum: $2.40 ; p<0.001$ ). These changes may have been due to the molar extrusion caused by RME and the vertical effect of the force vector applied by elastics. These findings are similar to those from many previous studies. ${ }^{13,20}$ It should be noted that changes in the glenoid fossa were not assessed in the current study; therefore we may need an in-depth analysis of such changes in future studies.

The upper incisors proclined significantly in the treatment group; a finding that is consistent with the previously published literature. ${ }^{13,21}$ However, the lower incisors retroclined more than reported previously. ${ }^{10}$ This amount of retrusion was greater than that reported in Moore's study $\left(-1.40^{\circ}\right) .{ }^{10}$ This difference could be due to the difference in the amount of overjet correction achieved in the 2 studies, which was greater in the present work (a mean of $5.87 \mathrm{~mm}$ as compared to $1.88 \mathrm{~mm}$ in Moore's study).

The amount of protrusion of the upper incisors was similar to that reported in many previous studies. ${ }^{13,21}$ However, the amount of retrusion of the lower incisors observed in the present study was almost double that reported in previous studies employing the RME procedure in conjunction with FM. ${ }^{13,21}$ This could be explained by the underlying biomechanics of the 2 systems. In the FM therapy, the frontal and mental bony regions were used as extraoral anchorage units to advance the maxilla, whereas in the ORTA therapy, the maxilla was moved forward using intermaxillary traction based on the intraoral elastics resting on the lower dental arch as the anchorage unit. This led to extra forces being transferred to the lower teeth, pushing them further in the posterior direction.

Although the retrusion of the lower incisors noted in the treatment group contributed to the overjet correction, the final inclination of the lower incisors at the end 
of the treatment was deemed unfavorable, as such severe retroclination may cause post-treatment relapse and possible dentoalveolar bony defects (e.g., fenestration or dehiscence).

Soft tissues improved significantly with the ORTA treatment, as both the upper and lower lips moved favorably, meaning that the upper lip moved forward and the lower lip backward, following dentoskeletal changes. This is similar to what was reported in previous studies. ${ }^{22,23}$

\section{Limitations}

One important limitation of the current study is its short-term evaluation period (i.e., patients were followed up for approx. 19 weeks). Therefore, the conclusions are confined only to the short-term perspective and future research work should focus on the prognosis of the achieved results. Another limitation is that the effect of gender on the treatment outcomes was not evaluated. Also, this study focused on 8-10-year-old patients and it would be interesting to see the skeletal and dentoalveolar effects in older age groups. More importantly, an analysis of patients' acceptance and of the levels of pain and discomfort associated with this treatment modality would be very valuable to clinicians.

\section{Generalizability}

As growth-related changes were filtered out by the reasonable homogeneity presented between the 2 groups in terms of age and type of malocclusion, it is expected that the results of this study reflect the effectiveness of the appliance, and hence could be generalized to all patients at the same age suffering from the same malocclusion. The short-term nature of the study does not allow us to make assumptions about the long-term stability of the results.

\section{Conclusions}

In the short-term, ORTA was an effective appliance to treat mild-to-moderate Class III malocclusion patients aged 8-10 years. The ORTA therapy led to a significant improvement in the intermaxillary relationship within 5 months of treatment, which was achieved by a forward movement of the maxilla as well as a backward and downward rotation of the mandible. In the current short period of observation, ORTA caused significant and favorable proclination of the upper incisors, and significant retroclination of the lower incisors, which was deemed undesirable.

\section{ORCID iDs}

Batool Ahmad Alzabibi (10) https://orcid.org/0000-0002-4337-813X Ahmad Sharafeddin Burhan (1) https://orcid.org/0000-0002-0727-2653 Mohammad Younis Hajeer (1) https://orcid.org/0000-0003-0640-1297 Fehmieh Rafik Nawaya (1) https://orcid.org/0000-0002-0225-3541

\section{References}

1. Morales-Fernández $M$, Iglesias-Linares $A$, Yañez-Vico RM, Mendoza-Mendoza A, Solano-Reina E. Bone- and dentoalveolaranchored dentofacial orthopedics for Class III malocclusion: New approaches, similar objectives? A systematic review. Angle Orthod. 2013;83(3):540-552. doi:10.2319/051312-392.1

2. Guyer EC, Ellis EE III, McNamara JA Jr., Behrents RG. Components of Class III malocclusion in juveniles and adolescents. Angle Orthod. 1986;56(1):7-30. doi:10.1043/0003-3219(1986)056<0007:COCIMI>2.0.CO;2

3. Woon SC, Thiruvenkatachari B. Early orthodontic treatment for Class III malocclusion: A systematic review and meta-analysis. Am J Orthod Dentofacial Orthop. 2017;151(1):28-52. doi:10.1016/j. ajodo.2016.07.017

4. Hägg U, Tse A, Bendeus M, Rabie ABM. A follow-up study of early treatment of pseudo Class III malocclusion. Angle Orthod. 2004;74(4):465-472. doi:10.1043/0003-3219(2004)074<0465:AFSOET>2.0.CO;2

5. Mandall N, Cousley R, DiBiase A, et al. Early Class III protraction facemask treatment reduces the need for orthognathic surgery: A multi-centre, two-arm parallel randomized, controlled trial. J Orthod. 2016;43(3):164-175. doi:10.1080/14653125.2016.1201302

6. Alarcón JA, Bastir M, Rosas A, Molero J. Chincup treatment modifies the mandibular shape in children with prognathism. Am J Orthod Dentofacial Orthop. 2011;140(1):38-43. doi:10.1016/j.ajodo.2009.10.046

7. Mandall N, DiBiase A, Littlewood S, et al. Is early Class III protraction facemask treatment effective? A multicentre, randomized, controlled trial: 15-month follow-up. J Orthod. 2010;37(3):149-161. doi:10.1179/14653121043056

8. Atalay Z, Tortop T. Dentofacial effects of a modified tandem traction bow appliance. Eur JOrthod. 2010;32(6):655-661 doi:10.1093/ejo/cjp153.

9. Martina R, D'Antò V, De Simone V, Galeotti A, Rongo R, Franchi L. Cephalometric outcomes of a new orthopaedic appliance for Class III malocclusion treatment. Eur J Orthod. 2020;42(2):187-192. doi:10.1093/ejo/cjz037

10. Moore KN. Cephalometric effects of Class III treatment: A comparison of ORTA ${ }^{\mathrm{TM}}$ and protraction facemask. Master of Science thesis. University of Illinois at Chicago; 2012.

11. Dahlberg G. Statistical methods for medical and biological students. BrMed J. 1940;2(4158):358-359.

12. Kim JH, Viana MA, Graber TM, Omerza FF, BeGole EA. The effectiveness of protraction face mask therapy: A metaanalysis. Am J Orthod Dentofacial Orthop. 1999;115(6):675-685. doi:10.1016/s0889-5406(99)70294-5

13. Ngan P, Yiu C, Hu A, Hägg U, Wei SH, Gunel E. Cephalometric and occlusal changes following maxillary expansion and protraction. Eur J Orthod. 1998;20(3):237-254. doi:10.1093/ejo/20.3.237

14. Pattanaik S, Mohammad N, Parida S, Sahoo SN. Treatment modalities for skeletal Class III malocclusion: Early to late treatment. IJSS Case Rep Rev. 2016;2(8):28-33. doi:10.17354/cr/2016/182

15. Zhang W, Qu HC, Yu M, Zhang Y. The effects of maxillary protraction with or without rapid maxillary expansion and age factors in treating Class III malocclusion: A meta-analysis. PloS One. 2015;10(6):e0130096. doi:10.1371/journal.pone.0130096

16. Farhadian N, Soheilifar S, Abolvardi M, Miresmailei A, Mohammadi Y. Effects of facemasks versus intraoral appliances in treating maxillary deficiency in growing patients: A systematic review and meta-analysis. Dent Med Probl. 2019;56(4):401-410. doi:10.17219/dmp/110738

17. Majanni AM, Hajeer MY. The removable mandibular retractor vs the bone-anchored intermaxillary traction in the correction of skeletal Class III malocclusion in children: A randomized controlled trial. J Contemp Dent Pract. 2016;17(5):361-371. doi:10.5005/jp-journals-10024-1856

18. Nienkemper M, Wilmes B, Pauls A, Drescher D. Maxillary protraction using a hybrid hyrax-facemask combination. Prog Orthod. 2013;14(1):5. doi:10.1186/2196-1042-14-5

19. Lin Y, Guo R, Hou L, Fu Z, Li W. Stability of maxillary protraction therapy in children with Class III malocclusion: A systematic review and meta-analysis. Clin Oral Investig. 2018;22(7):2639-2652. doi:10.1007/s00784-018-2363-8

20. Husson AH, Burhan AS, Salma FB, Nawaya FR. Dentoskeletal effects of the modified tandem appliance vs the facemask appliance in the treatment of skeletal Class III malocclusion: A single-center, randomized controlled trial. J Contemp Dent Pract. 2016;17(7):522-529. 
21. Ngan P, Wilmes B, Drescher D, Martin C, Weaver B, Gunel E. Comparison of two maxillary protraction protocols: Tooth-borne versus bone-anchored protraction facemask treatment. Prog Orthod. 2015;16:26 doi:10.1186/s40510-015-0096-7.

22. Lee NK, Yang IH, Baek SH. The short-term treatment effects of face mask therapy in Class III patients based on the anchorage device: Miniplates vs rapid maxillary expansion. Angle Orthod. 2012;82(5):846-852. doi:10.2319/090811-584.1

23. Ge YS, Liu J, Chen L, Han JL, Guo X. Dentofacial effects of two facemask therapies for maxillary protraction. Angle Orthod. 2012;82(6):1083-1091. doi:10.2319/012912-76.1 